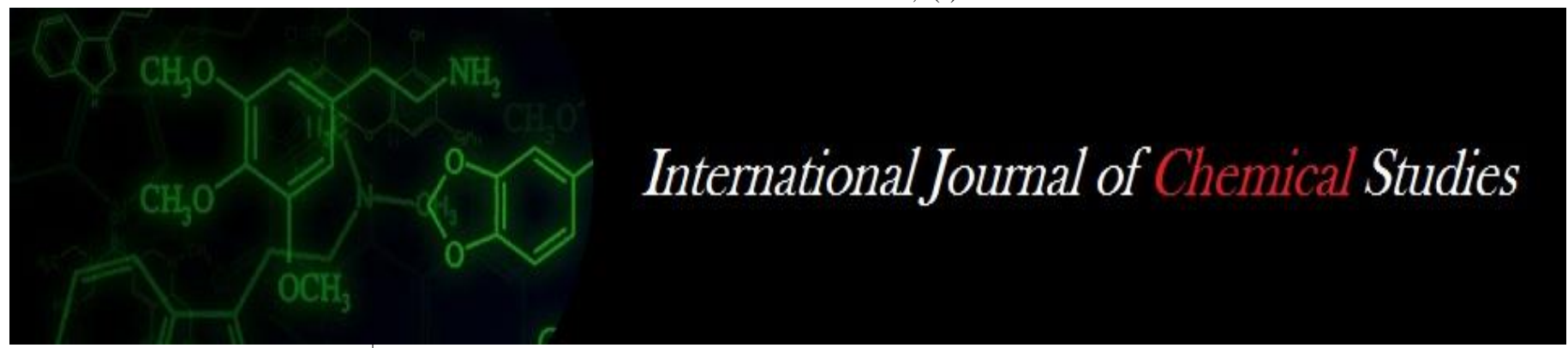

P-ISSN: 2349-8528

E-ISSN: 2321-4902

www.chemijournal.com

IJCS 2021; 9(1): 1386-1389

(C) 2021 IJCS

Received: 06-11-2020

Accepted: 14-12-2020

\section{Sri Lakshmi}

Department of Genetics and Plant Breeding, Agricultural College, Bapatla, Andhra

Pradesh, India

Y Suneetha

Agricultural Research Station,

Bapatla, Andhra Pradesh, India

\section{T Srinivas}

Department of Genetics and Plant Breeding, Agricultura College, Bapatla, Andhra Pradesh, India
Corresponding Author:

Y Suneetha

Agricultural Research Station,

Bapatla, Andhra Pradesh, India

\section{Genetic diversity analysis for grain yield and yield components in rice}

\author{
M Sri Lakshmi, Y Suneetha and T Srinivas
}

DOI: https://doi.org/10.22271/chemi.2021.v9.i1t.11416

\begin{abstract}
The present investigation was undertaken with 82 rice genotypes to estimate genetic divergence of the genotypes for yield and yield components. The study involved 70 genotypes from Maruteru, six from Machilipatnam, three from Bapatla, two from Phillippines and one from Pulla. The diversity was evaluated using multivariate analysis technique of Mahalanobis $\mathrm{D}^{2}$. The 82 rice genotypes studied were grouped into ten clusters. Cluster IV was observed to be the largest with 22 genotypes, followed by Cluster I with 17 genotypes and Cluster V with 13 genotypes. The clusters, VII, VIII, IX and X were monogenotypic. The pattern of distribution of genotypes into various clusters was observed to be at random with no relation to geographical diversity. Results on inter-cluster distances revealed maximum diversity between genotypes of cluster IX and cluster X, while intra-cluster distance was noticed to be maximum for cluster V. Cluster III had recorded maximum grain yield per plant. Further, maximum contribution towards genetic divergence was noticed by filled grains per plant $(47.03 \%)$, followed by illfilled grains per plant $(21.92 \%)$ and minimum by days to 50 per cent flowering $(0.01 \%)$.
\end{abstract}

Keywords: Rice, genetic divergence, grain yield and yield components

\section{Introduction}

Genetic divergence studies play a key role in analyzing of genetic diversity among the genotypes and aid in the selection of diverse parents towards realization of enhanced levels of heterosis in addition to wide range of variability for effective selection. Multivariate analysis like Mahalanobis $\mathrm{D}^{2}$ statistic provides an useful tool for measuring the genetic diversity in a given population with respect to different characters considered together. Further, the problem of selecting diverse parents for hybridization programme is narrowed with the identification of characters responsible for discrimination between the genotypes. This is essential in major crops like rice, a source of food for about three million people worldwide to break the yield plateaus being observed in the crop. The present investigation was undertaken in this direction to estimate genetic diversity of rice genotypes studied for their utilization in crop improvement programs aimed at the development of high yielding rice varieties.

\section{Material and Methods}

The experimental material consisted of 82 rice genotypes obtained from Regional Agricultural Research Station, Maruteru (70 Nos.); Agricultural Research Station, Machilipatnam (6 Nos.); Agricultural Research Station, Bapatla (3 Nos.), International Rice Research Institute, Philippines (2 Nos.) and Agricultural Research Station, Pulla (1 No.). All the 82 genotypes were sown at Regional Agricultural Research Station, Maruteu during Rabi 2016-17 on separate raised nursery beds. All recommended package of practices were adopted to raise a healthy nursery and thirty days old seedlings were transplanted in the main field laid out in Randomized Block Design (RBD) with three replications. Each genotype was transplanted separately in three rows of $2 \mathrm{~m}$ length by adopting a spacing of $20 \mathrm{~cm}$ between rows and $15 \mathrm{~cm}$ between plants. All recommended package of practices were adopted throughout the crop growth period and need based plant protection measures were taken up to raise a healthy crop. Observations were recorded on five randomly selected plants for grain yield per plant and yield component characters, namely, plant height, total tillers per plant, ear bearing tillers per plant, panicle length, filled grains per panicle and ill-filled grains per panicle. Observations on days to 50 per cent flowering and days to maturity were recorded on plot basis. 
In contrast, observations for 100 seed weight were obtained from a random grain sample drawn from each plot in each genotype and replication using standard procedures. The data collected was subjected to standard statistical procedures given by Panse and Sukhatme (1978). Genetic divergence analysis was done following the $\mathrm{D}^{2}$ statistics proposed by Mahalanobis (1928) ${ }^{[3]}$ and described by Rao (1952) ${ }^{[6]}$. The analysis was carried out using the software Window Stat Version 8.5.

\section{Results and Discussion}

The results on genetic divergence of 82 rice genotypes for grain yield and yield components are presented in Tables 1-4. The 82 rice genotypes were grouped into 10 clusters using Tocher's method based on $\mathrm{D}^{2}$ value such that the genotypes belonging to the same cluster (Intra-cluster) had an average smaller $\mathrm{D}^{2}$ value than those belonging to different clusters (Inter-cluster). The distribution of 82 genotypes into ten clusters is presented in Table 1. A perusal of the results revealed Cluster IV to be the largest comprising of 22 genotypes (MTU 1031, MTU 1071, MTU 1064, MTU 5293, MTU 7029, MTU 2077, MTU 1226, TCNP 97, MTU 3626, BPT 3291, MTU 1184, MCM 100, MCM 41, STBN 12-5, MTU 5182, MCM 27, TCNP 73, MTU 1006, TCNP 58, IR 7693-2B-7, TCNP 72 and TCNP 119), representing rice genotypes collected from Maruteru, Machilipatnam, Philippines and Bapatla. Cluster I consisted of 17 genotypes (TCNP 80,MTU 2231, MTU 1121,TCNP 26,BPT 5204, MTU 1194, TCNP 78, TCNP 22, TCNP 124, TCNP 118, TCNP 114, TCNP 64, TCNP 170, TCNP 87, MTU 5249, BPT 2270 and TCNP 94), including genotypes collected from Maruteru and Bapatla. However, Cluster III (E 460, TCNP 65, TCNP 14, TCNP 13, TCNP 56, E 456, TCNP 51, TCNP 83, MTU 1187, TCNP 177 and TCNP 75) and Cluster VI (MTU 1061, MTU 2716, MTU 1001, MTU 1032 and MTU 1112) consisted of only genotypes from Maruteru. The genotypes in Cluster VI are all released or pre-release varieties, while the genotypes in Cluster III are all advanced breeding lines. Cluster VII (TCNP 70), Cluster VIII (TCNP 29), Cluster IX (MTU 1224) and Cluster X (MCM 223) were observed to be monogenotypic clusters, with one genotype each. The mode of distribution of genotypes from different geographical regions into various clusters was thus observed to be at random indicating no relation of geographic and genetic diversity. Genotypes chosen from the same eco-geographical region were observed to be present in different clusters as well as in same cluster, while genotypes from diverse geographical regions were also included in different clusters as well as the same cluster. The findings are in conformity with the reports of Kumar et al. (2020) [2]. This random grouping may be attributed to the exchange of breeding material over locations and further intensive natural and human selection for diverse and adaptable gene complexes resulting in genetic drift and consequently increased genetic diversity (Arunachalam and Ram, 1967) ${ }^{[1]}$.

The results on average intra and inter-cluster $\mathrm{D}^{2}$ values are presented in Table 2. A perusal of these results on intracluster distances, indicative of the diversity among the genotypes grouped in that cluster revealed intra-cluster $\mathrm{D}^{2}$ values to range from 0.000 (Clusters VII, VIII, IX and X) to 288.55 (Cluster V). Maximum intra-cluster $\mathrm{D}^{2}$ value was 288.55 for cluster V, followed by 210.37 for cluster VI and 143.95 for cluster IV, indicating that genotypes from these clusters were relatively highly divergent meriting their consideration in selection of parents for hybridization. However, the intra-cluster distance was zero for the monogenotypic clusters, VII, VIII, IX and X. Further, greater the distance between two clusters, wider is the genetic diversity expected between genotypes of the two clusters. In the present study, maximum inter-cluster distance was observed between Cluster IX and X (2415.87). Therefore, hybridization between the genotypes of Cluster IX (MTU 1224) with MCM 223 genotype of cluster $X$ is expected to result in greater variability and transgressive segregants. Minimum inter-cluster distance was observed between Cluster I and Cluster II (124.23), indicating their relatively closer relationship and similarity with regards to the characters studied for most of the genotypes in the two clusters.

A perusal of the results on cluster means presented in Table 3 indicates average performance of all genotypes present in a particular cluster for the character. Estimate of cluster means provides information on suitable donors for improvement of particular traits. The cluster means for grain yield and yield components for the 82 genotypes studied in the present investigation revealed considerable differences between the clusters for all characters under study. The cluster means ranged from 82.33 days (Cluster X) to 112.67 (Cluster VI) for days to 50 per cent flowering; 112.33 days (Cluster $\mathrm{X}$ ) to 142.67 days (Cluster VI) for days to maturity; $100.20 \mathrm{~cm}$ (Cluster IX) to $142.60 \mathrm{~cm}$ (Cluster X) for plant height; 10.80 (Cluster X) to 16.40 (Cluster IX) for total tillers per plant; 8.80 (Cluster X) to 14.40 (Cluster IX) for ear bearing tillers per plant; $24.50 \mathrm{~cm}$ (Cluster IX) to $29.50 \mathrm{~cm}$ (Cluster X) for panicle length; 85.00 (Cluster IX) to 460.00 (Cluster X) for filled grains per panicle; 19.64 (Cluster III) to 103.00 (Cluster $\mathrm{X})$ for ill filled grains per panicle; $1.27 \mathrm{~g}$ (Cluster VIII) to $2.12 \mathrm{~g}$ (Cluster II) for 100 seed weight; $14.51 \mathrm{~g}$ (Cluster VII) to $40.74 \mathrm{~g}$ (Cluster III) for grain yield per plant in the present study. There was no single cluster with all the desirable traits, which ruled out the possibility of direct selection of genotypes for immediate use. The results are in broad agreement with the reports of Sudeepthi et al. (2020) [7]. Selection of genotypes from clusters with high mean for the respective traits is suggested for utilization in hybridization programmes aimed at improvement of the respective traits. Further, hybridization between the selected genotypes from divergent clusters is suggested for judicious combination of all the targeted traits. In this direction, selection of genotypes from the clusters, III and $\mathrm{X}$ is suggested for utilization in hybridization programmes aimed at the development of high yielding rice genotypes with greater panicle length and filled grains per panicle.

Information on the relative contribution of various characters towards divergence was reported to aid the breeder in choice of parents for hybridization and effective selection (Prasad et al., 2018) ${ }^{[5]}$. A perusal of the results on per cent contribution towards genetic divergence by the yield and yield component characters studied in the present investigation is presented in Table 4. A perusal of these results revealed maximum contribution towards genetic divergence by filled grains per panicle $(47.03 \%)$, followed by ill-filled grains per panicle $(21.92 \%)$, grain yield per plant $(17.88 \%)$ and days to maturity $(12.07 \%)$. Hence, selection for divergent parents based on filled and ill-filled grains per panicle would be useful for increasing scope of isolating desirable recombinants in breeding of high yielding rice genotypes. 
Table 1: Clustering pattern of 82 rice genotypes for grain yield and yield component characters in rice

\begin{tabular}{|c|c|c|c|}
\hline \begin{tabular}{|l|} 
Cluster \\
number
\end{tabular} & $\begin{array}{c}\text { Number of } \\
\text { genotypes }\end{array}$ & Genotype & Source \\
\hline I & 17 & \begin{tabular}{|l} 
TCNP 80,MTU 2231, MTU 1121,TCNP 26,BPT 5204, MTU 1194, TCNP 78, TCNP 22, TCNP \\
124, TCNP 118, TCNP 114, TCNP 64, TCNP 170, TCNP 87, MTU 5249, BPT 2270 and TCNP 94
\end{tabular} & Bapatla, Maruteru \\
\hline II & 10 & $\begin{array}{c}\text { IRT 11176, MTU 1156, STBN 12-10, MTU 1153, MTU 1140, MTU 2067, MCM 48, MCM 225, } \\
\text { IR } 64 \text { and MTU } 1010\end{array}$ & $\begin{array}{c}\text { Philippines, Maruteru, } \\
\text { Machilipatnam }\end{array}$ \\
\hline III & 11 & $\begin{array}{c}\text { E 460, TCNP 65, TCNP 14, TCNP 13, TCNP 56, E 456, TCNP 51, TCNP 83, MTU 1187, TCNP } \\
177 \text { and TCNP 75 }\end{array}$ & Maruteru \\
\hline IV & 22 & $\begin{array}{l}\text { MTU 1031, MTU 1071, MTU 1064, MTU 5293, MTU 7029, MTU 2077, MTU 1226, TCNP } 97, \\
\text { MTU 3626, BPT 3291, MTU 1184, MCM 100, MCM 41, STBN 12-5, MTU 5182, MCM 27, } \\
\text { TCNP 73, MTU 1006, TCNP 58, IR 7693-2B-7, TCNP 72 and TCNP } 119\end{array}$ & $\begin{array}{c}\text { Maruteru, } \\
\text { Machilipatnam, } \\
\text { Philippines, Bapatla } \\
\end{array}$ \\
\hline $\mathrm{V}$ & 13 & $\begin{array}{c}\text { MTU 1210, MTU 4870, TCNP 61, TCNP 90, MTU 1075, E 467, TCNP 21, TCNP 106, MTU } \\
\text { 1078, PLA 1100, TCNP 38, MTU } 1229 \text { and TCNP } 81\end{array}$ & Maruteru, Pulla \\
\hline VI & 5 & MTU 1061, MTU 2716, MTU 1001, MTU 1032 and MTU 1112 & Maruteru \\
\hline VII & 1 & TCNP 70 & Maruteru \\
\hline VIII & 1 & TCNP 29 & Maruteru \\
\hline IX & 1 & MTU 1224 & Maruteru \\
\hline $\mathrm{X}$ & 1 & MCM 223 & Machilipatnam \\
\hline
\end{tabular}

Table 2: Average intra-and inter-cluster $\mathrm{D}^{2}$ values among ten clusters of rice genotypes for grain yield and yield components

\begin{tabular}{|c|c|c|c|c|c|c|c|c|c|c|}
\hline Cluster & I & II & III & IV & V & VI & VII & VIII & IX & X \\
\hline I & 60.73 & 385.76 & 124.23 & 146.28 & 370.52 & 326.04 & 261.80 & 522.56 & 949.39 & 1171.86 \\
\hline II & & 80.67 & 527.43 & 326.90 & 979.27 & 423.57 & 827.26 & 671.85 & 474.53 & 2090.60 \\
\hline III & & & 95.19 & 267.79 & 395.28 & 498.73 & 239.99 & 619.15 & 1173.42 & 1063.85 \\
\hline IV & & & & 143.95 & 473.66 & 314.81 & 444.60 & 477.02 & 746.03 & 1354.74 \\
\hline V & & & & & 288.55 & 693.17 & 506.75 & 406.02 & 1180.10 & 718.03 \\
\hline VI & & & & & & 210.37 & 971.03 & 726.05 & 628.08 & 2098.39 \\
\hline VII & & & & & & & 0.00 & 750.84 & 1730.87 & 656.28 \\
\hline VIII & & & & & & & & 0.00 & 464.81 & 775.69 \\
\hline IX & & & & & & & & & 0.00 & 2415.87 \\
\hline X & & & & & & & & & & \\
\hline
\end{tabular}

Table 3: Cluster means for grain yield and yield component characters of 82 rice genotypes

\begin{tabular}{|c|c|c|c|c|c|c|c|c|c|c|}
\hline Cluster & $\begin{array}{c}\text { Days to } \\
50 \% \text { flowering }\end{array}$ & $\begin{array}{c}\text { Days to } \\
\text { maturity }\end{array}$ & \begin{tabular}{|l|} 
Plant \\
height t
\end{tabular} & \begin{tabular}{|c|} 
Total \\
tillers/plant
\end{tabular} & $\begin{array}{l}\text { Ear bearing } \\
\text { tillers/plant }\end{array}$ & $\begin{array}{l}\text { Panicle } \\
\text { length }\end{array}$ & $\begin{array}{c}\text { Filled } \\
\text { grains/panicle }\end{array}$ & $\begin{array}{c}\text { Ill filled } \\
\text { grains/panicle }\end{array}$ & $\begin{array}{c}\text { 100- seed } \\
\text { weight }\end{array}$ & $\begin{array}{c}\text { Grain yield } \\
\text { per plant }\end{array}$ \\
\hline I & 98.92 & 128.92 & 111.86 & 13.25 & 11.25 & 24.81 & 256.57 & 21.14 & 1.75 & 28.19 \\
\hline II & 84.93 & 114.93 & 110.99 & 11.43 & 9.43 & 24.59 & 151.37 & 19.81 & 2.12 & 15.59 \\
\hline III & 92.39 & 122.39 & 111.96 & 13.72 & 11.72 & 25.20 & 277.03 & 19.64 & 2.00 & 40.74 \\
\hline IV & 99.23 & 129.23 & 112.44 & 13.21 & 11.26 & 24.68 & 227.56 & 29.11 & 1.92 & 21.96 \\
\hline $\mathrm{V}$ & 104.33 & 134.33 & 108.98 & 13.04 & 11.04 & 25.28 & 303.74 & 66.00 & 1.71 & 38.91 \\
\hline VI & 112.67 & 142.67 & 103.77 & 14.97 & 12.97 & 28.98 & 154.20 & 25.53 & 1.94 & 37.59 \\
\hline VII & 85.33 & 115.33 & 110.44 & 12.90 & 10.90 & 24.94 & 365.33 & 20.33 & 1.29 & 14.51 \\
\hline VIII & 91.33 & 121.33 & 118.00 & 14.20 & 12.20 & 26.49 & 249.67 & 100.67 & 1.27 & 23.13 \\
\hline IX & 94.67 & 124.67 & 100.20 & 16.40 & 14.40 & 24.50 & 85.00 & 85.67 & 1.44 & 26.53 \\
\hline$X$ & 82.33 & 112.33 & 142.60 & 10.80 & 8.80 & 29.50 & 460.00 & 103.00 & 1.77 & 20.40 \\
\hline
\end{tabular}

Table 4: Relative contribution of the characters studied for genetic diversity in the rice genotypes evaluated

\begin{tabular}{|c|c|c|}
\hline S. No & Character & Contribution (\%) \\
\hline 1 & Days to 50\% flowering & 0.01 \\
\hline 2 & Days to maturity & 12.07 \\
\hline 3 & Plant height & 0.27 \\
\hline 4 & Total tillers per plant & 0.45 \\
\hline 5 & Ear bearing tillers per plant & 0.04 \\
\hline 6 & Panicle length & 0.05 \\
\hline 7 & Filled grains per panicle & 47.03 \\
\hline 8 & Ill filled grains per panicle & 21.92 \\
\hline 9 & 100- seed weight & 0.27 \\
\hline 10 & Grain yield per plant & 17.88 \\
\hline
\end{tabular}

\section{Conclusions}

The results suggest hybridization between MTU 1224 of Cluster IX with MCM 223 genotype of Cluster $\mathrm{X}$ for realization of transgressive segregants towards development of high yielding genotypes. Further, filled and ill-filled grains per panicle were identified as important traits contributing maximum for genetic divergence in the rice genotypes studied.

\section{References}

1. Arunachalam V, Ram J. Geographical diversity in relation to genetic divergence in cultivated sorghum. Indian Journal of Genetics and Plant Breeding 1967;27:369-380.

2. Kumar Saurabh Singh, Suneetha Y, Vinay Kumar G, Srinivasa Rao V, Sandeep Raja DT. Srinivas. Genetic Divergence Studies for Yield and Quality Traits in Coloured Rice. Journal of Pharmacognosy and Phytochemistry 2020;9(4):1234-1240.

3. Mahalanobis PC. A statistical study at Chinese head measurement. Journal of Asiatic Society of Bengal 1928;25:301-307.

4. Panse VG, Sukhatme PV. Statistical Methods for Agricultural Workers. Indian Council of Agricultural Research, New Delhi 1967, 103-108. 
5. Prasad RKK, Suneetha Y, Srinivas T. Genetic diversity studies in rice (Oryza sativa L.). Electronic Journal of Plant Breeding 2018;9(4):1335-1341.

6. Rao CR. Advanced Statistical Methods in Biometrical Research. John Wiley and sons. New York 1952, 236272.

7. Sudeepthi K, Srinivas T, Ravikumar BNVSR, Jyothula DPB, Nafeez Umar SK. Genetic divergence studies for yield and yield component traits in rice (Oryza sativa L.). Multilogic in science 2020;9:415-418. 